\title{
Os Sete Saberes Indispensáveis à Educação do Futuro
}

\author{
Maria do Socorro Cecílio Sobral ${ }^{1}$; Maria das Graças Carvalho ${ }^{2}$; Ana Dandara da Silveira Carvalho ${ }^{3}$
}

\begin{abstract}
Resumo: O presente trabalho é uma resenha da obra "Os sete saberes indispensáveis à educação do Futuro" de Edgar Morin. Este, considerado como um dos maiores pensadores do século XX, é sociólogo, antropólogo, historiador, geógrafo, filósofo, tem mais de 40 livros publicados e traduzidos em diversas línguas. É um apaixonado pelas obras em geral e, durante a II Guerra Mundial, foi combatente voluntário da resistência francesa, lutando pelo nazismo e o stalismo.
\end{abstract}

Palavras Chaves: Educação; Saberes indispensáveis; Educação do Futuro.

\section{The Seven Indispensable Knowledge for the Future Education}

\begin{abstract}
This paper is a review of the book "The seven knowledge essential to the education of the Future" by Edgar Morin. This, considered one of the greatest thinkers of the twentieth century, is a sociologist, anthropologist, historian, geographer, philosopher, has more than 40 published and translated into several languages books. It is a love with the building works and, during World War II, was a volunteer fighter of the French Resistance, fighting for Nazism and Stalinism.
\end{abstract}

Key words: Education; Essential knowledge; Future Education.

\section{Dados sobre a obra}

Os sete saberes necessários a educação do futuro/ Edgar Morin: tradução de Catarina Eleonora F. Silva e Jeanne Sawaya, 2a ed.São Paulo; Cortez ; Brasília,DF ; UNESCO, 2000. Apresenta sete Capítulos em 116 páginas.

\section{Introdução}

Trata-se da tradução de uma obra original do autor, uma de suas mis famosas, na qual afirma que, diante a complexidade dos dilemas sociais contemporâneos, apenas os estudos de caráter inter, poli e transdisciplinares é que poder-se-iam obter algum resultado satisfatório em termos comportamentais e atitudinais dos indivíduos.

\footnotetext{
${ }^{1}$ Graduada em Ciências Biológicas pela Universidade Regional do Cariri. Pós graduada em Ensino de Biologia pela Universidade de Pernambuco e em Metodologia do Ensino Superior pela Universidade Católica de Pernambuco. Programa de Pós-Graduação em Educação em Ciências: Química da Vida e Saúde da Universidade Federal do Rio Grande do Sul - UFRS.

Contato: socorrosobral@bol.com.br.

${ }^{2}$ Mestranda em Ciências da Educação pela Universidade Lusófona - PT. Especialização em Docência do Ensino Superior. E-mail: grace.arthur@hotmail.com;

${ }^{3}$ Mestranda em Ciências da Educação pela Universidade Lusófona - PT. Especialização em Docência do Ensino Superior. E-mail: ana.dandara@hotmail.com;
} 
Chega mesmo o autor a nos desafiar, indagando sobre para que afinal serviriam todos os saberes acumulados durante a formação, senão para nos dar respostas a nossas expectativas, aos nossos desejos e as nossos questionamentos?. Daí a motivação para esta resenha crítica, que apresentaremos mais detalhadamente a seguir, do manuscrito que o próprio autor original denomina de inspirações para que o educador possa basear sua prática educacional.

\section{Os Sete Saberes Indispensáveis à Educação do Futuro}

O presente estudo propõe-se a apresentar, de maneira sintética e crítica, uma avaliação crítica do manuscrito de Edgar Morin, à partir da tradução das autoras Catarina Eleonora F. Silva e Jeanne Sawaya, apresentando as suas ideias sobre a educação do futuro, onde incorpora-se algumas contribuições particulares das autoras do estudo.

Uma resenha é uma espécie de resumo, onde se faz uma crítica ao tempo em que se estabelece uma comparação com outra obra de uma mesma área. Normalmente permite algum comentário ou juízo de valor, de forma que vai exigir de quem o faz, um profundo conhecimento para que possa discutir tais ideias (NASCIMENTO e PÓVOAS, 2002).

No nosso caso, optamos por uma resenha do tipo descritiva crítica, onde embora apresentando os elementos informativos da obra, iremos tão somente incluir o julgamento que o grupo achar pertinente e adequado (NASCIMENTO e PÓVOAS, 2002), já que este representará nossa contribuição científica mais efetiva.

A ideia principal de uma resenha é manter-se o referencial do autor, que no caso em foco, prioriza a humanização da educação, evitando que os atuais processos educativos caiam em estado inercial, evitando-se dessa forma, sua evolução natural. Esta neste caso, se daria de forma compassada e, de acordo com as novas demandas e realidades sociais a nós apresentadas.

A autora inicia sua tradução com uma pequena autobiografia do autor principal da obra "Os sete saberes necessários a educação do futuro" , Edgar Morin , considerado como um dos maiores pensadores do século XX. É sociólogo, antropólogo, historiador, geógrafo, filósofo, com mais de 40 livros publicados e traduzidos em diversas línguas. Um apaixonado pelas obras em geral e que durante a II Guerra Mundial, foi combatente voluntário da resistência francesa, lutando pelo nazismo e o stalismo.

Por ser atuante e muito preparado, em 1999 a Unesco, solicitou ao mesmo que organizasse um conjunto de reflexões, que pudesse servir como ponto de partida para repensar a educação do século XXI. Esse trabalho resultou no livro que fundamenta essa resenha, o qual propõe novos caminhos para formação de cidadãos do mundo. Os sete saberes anunciados por Morin são os seguintes: 
Primeiro: " Evitar as cegueiras do conhecimento: o erro e a ilusão"- o conhecimento nunca é um espelho da realidade, é sempre uma tradução seguida de reconstrução, comportando o risco de erro e ilusão, tomar um simples ideia como algo real é um equívoco. As possibilidades de erro e ilusão são múltiplas, algumas provenientes do exterior cultural e social, inibem a autonomia da mente e impedem a busca da verdade; outras são vindas do interior encerradas, as vezes no seio de nossos melhores meios de conhecimento, fazem com que as mentes se equivoquem de si própria e sobre si mesmas. A educação deve-se dedicar, identificação de erros, ilusões e cegueiras, promovendo o desenvolvimento científico civilizando cada vez mais as teorias na busca de verdade para que as novas gerações sejam abertas, racionais, criticas, reflexivas e preparadas para o inesperado.

Segundo: "Os princípios do conhecimento pertinente" - o conhecimento do mundo como mundo é necessário ao mesmo tempo intelectual e vital. Só com o acesso as informações do mundo é possível articulá-las e para fazer isso é necessário a reforma do pensamento nesse sentido a educação deve favorecer a aptidão natural da mente em formular e resolver problemas essências e, de forma correlata, estimular o uso da inteligência geral para organizar o saber disperso, unificando-o para considerar o contexto e o complexo planetário.

Terceiro: "Ensinar a condição humana" - implica em conhecer o humano, situando-o no universo, sem separá-lo dele, reconhecendo o enraizamento no cosmos físico e na esfera viva, porque o humano é a um só tempo cósmico e terrestre, como é também a um só tempo biológico e plenamente cultural, não há cultura sem cérebro humano. A educação precisa considerar o destino mutifacetado do humano: o destino da espécie humana, o destino individual, o destino social, o destino histórico, todos entrelaçados e inseparáveis para uma tomada de consciência sobre nosso enraizamento como cidadãos da Terra.

Quarto: "Ensinar a identidade terrena" - como cidadãos, é preciso que compreendamos a condição humana no mundo como a condição do mundo no humano, que com a evolução da história moderna, se tornou condição da era planetária. É necessário ensinar que não é suficiente reduzir a um só a complexidade dos problemas importantes do planeta, como a demografia, a escassez de alimentos, a bomba atômica ou a ecologia. Os problemas estão todos amarrados uns aos outros. É preciso mostrar que a humanidade vive agora um destino comum. A união planetária é a exigência racional mínima de um mundo interdependente para uma transformação global, que retroagiria sobre as transformações individuais.

Quinto: "Enfrentar as incertezas" - grande conquista da inteligência seria poder enfim se libertar da ilusão de prever o destino humano, mas o futuro permanece aberto e imprevisível. $\mathrm{Na}$ 
história da humanidade acontece diariamente fatos inesperados. Existem inovações e destruições a todo momento, dessa forma a realidade não é facilmente legível, por isso importa interpretar a realidade antes de reconhecer onde está o realismo, mesmo que o conhecimento tenha o risco do erro mas é o ato cognitivo que constitui a oportunidade de chegar ao conhecimento pertinente. A ecologia da ação é considerar toda complexidade da qual ela supõe, o acaso, o inesperado, imprevisto, consciência de derivas e transformações. A escola precisa ensinar as certezas e mostrar na história quantos inesperados acontecem afim de possam ser enfrentados.

Sexto: “Ensinar a compreensão" - é papel da educação, sem dúvida, há importantes progressos da compreensão, por que a comunicação triunfa e ainda assim não garante a compreensão e desse modo há uma conjunção de incompreensões; intelectual, humana, individual, coletiva, constituindo obstáculos para melhoria das relações entre indivíduos, grupos, povos, nações.A ética da compreensão é a arte de viver que nos demanda em primeiro lugar de modo desinteressado. A ética da compreensão pede que se compreenda a incompreensão. Compreender inclui um processo de empatia, de identificação e de projeção, pedindo abertura simpatia e generosidade A compreensão é ao mesmo tempo meio e fim da comunicação humana. O planeta necessita, em todos os sentidos, de compreensões mútuas. Dada a importância da educação para compreensão em todos os níveis educativos e em todas as idades, o desenvolvimento da compreensão necessita da reforma planetária das mentalidades; esta deve ser a tarefa da educação do futuro.

Sétimo: "Ética do gênero humano" - a concepção complexa do gênero humano comporta a tríade indivíduo/ sociedade/ espécie, cada um desses termos é ao mesmo tempo meio e fim uns dos outros e significa o desenvolvimento conjunto das autonomias individuais, das participações comunitárias e do sentimento de pertencer a espécie humana. No seio dessa tríade complexa emerge a consciência comum e solidariedade planetária do gênero humano no sentido democrático para realização da humanidade pelo acesso a cidadania terrena.

Pelo exposto e, ao que nos parece, a educação do futuro exige um esforço transdisciplinar, que seja capaz de rejuntar ciências e humanidades. Capaz de romper com a oposição entre natureza e cultura. Edgar Morin, nesses "sete saberes", expõe um desafio cognitivo a todos os pensadores empenhados em repensar os rumos que as instituições educacionais terão que assumir para garantirem ás futuras gerações um mundo com mais beleza e sustentabilidade.

Trata-se pois de uma obra que vem ao encontro de muitas das demandas dos educadores interessados em reconstruir o processo educativo, visando aprimorá-lo e adequá-lo às novas realidades. 


\section{Conclusão}

Após a leitura do texto em questão, em que o autor parece apresentar os "sete saberes" muito mais como desafios didáticos para uma educação futurística, buscando uma sociedade que preserve cada vez mais os valores humanos, que prime por uma identidade cada vez mais humana. A ideia do autor, parece ser a de preparar a sociedade para os desafios de um quotidiano cheio de intempéries sociais de impacto nas relações sociais.

Entretanto, observe-se com certa parcimônia a implementação de tais assertivas, pois que tais mudanças repentinas no comportamento social dos indivíduos, não ocorrem nessa velocidade. Principalmente numa sociedade como a nossa, ainda pouco solidária, aonde valores éticos são pouco praticados e valorizados e, onde a educação ainda não é contemplada com a importância que realmente deveria ter.

Dessa forma, a propagação dos "sete saberes" de Morin, precisa de maior divulgação, para que possa tomar forma, de maneira que cada educador possa apropriar-se de suas ideias, tornando-as um referencial em si mesmo. Um princípio-guia de suas ações. Dessa forma, é possível se pensar que, possa sim, ser desencadeado um novo e amplo processo de mudança de comportamento, capaz de exercer algum impacto positivo, gerador de uma maior qualidade nas nossas atitudes solidárias comportamentais e de relacionamento.

\section{Referências:}

MORIN, Edgar . Tradução de Catarina Eleonora F. Silva e Jeanne Sawaya, $2^{a}$ ed.São Paulo; Cortez ; Brasília,DF ; UNESCO, 2000;

NASCIMENTO, Dinalva Melo do; PÓVOAS, Ruy do Carmo. Metodologia do Trabalho Científico: teoria e prática. Rio de Janeiro: Forense S/A, 2002, 184 p.

\section{Como citar este artigo (Formato ABNT):}

SOBRAL, Maria do Socorro C. CARVALHO, Maria das Graças; NASCIMENTO, Maria Cristina D. Os Sete Saberes Indispensáveis à Educação do Futuro. Id on Line Revista de Psicologia, Novembro de 2015, vol.9, n.28, p. 106-110. ISSN 1981-1189.

Recebido: $14 / 08 / 2015$

Aceito: $15 / 09 / 2015$ 